\title{
PENGARUH KONSUMSI KUNYIT ASAM TERHADAP DYSMENORRHOEA
}

\author{
Ambika Kurnia Mustikawati \\ Akademi Kebidanan Harapan Mulya Ponorogo \\ Email :ambikadirham06@gmail.com
}

\begin{abstract}
Abstrak
Penelitian ini bertujuan untuk mengetahui seberapa besar konsumsi kunyit asam mempengaruhi dysmeorrhoea pada mahasiswi Akademi Kebidanan Harapan Mulya Ponorogo. Metode penelitian menggunakan pre experimental dengan pendekatan kuantitatif yang sudah dilakukan pada bulan Desember 2019. Besar sampel dalam penelitian sebanyak 11 orang tiap kelompok terdiri dari kelompok kontrol dan kelompok intervensi. Instrumen yang digunakan pada variabel ini adalah lembar observasi dan lembar penilaian skala nyeri Bourbonnais untuk mengumpulkan data dengan mengadakan pengamatan secara langsung kepada responden untuk mencari perubahan atau hal-hal yang akan diteliti. Data yang terkumpul di uji statistik menggunakan uji Wilcoxon. Hasil penelitian menunjukkan hampir sebagian besar dari responden yaitu 7 (63.6\%) mengalami nyeri sedang, sedangkan pada kelompok intervensi sesudah diberikan kunyit asam didapatkan bahwa sebagian besar responden yaitu $6(54.5 \%)$ mengalami nyeri ringan. Hasil uji statistik Wilcoxon dengan taraf signifikan 0,05 yaitu diperoleh $p=0,001$ sehingga $p<\alpha 0,05$ maka $\mathrm{H}_{0}$ ditolak. Saran bagi mahasiswa diharapkan untuk mengkonsumsi kunyit asam sebagai salah satu upaya meringankan dysmenorrhea secara alami sehingga bisa meminimalkan apabila terjadi efek samping.
\end{abstract}

Kata kunci : Konsumsi, kunyit asam, dysmenorrhea

\begin{abstract}
This study aims to determine how much consumption of acid turmeric affects dysmeorrhoea in Harapan Mulya Ponorogo Academy students. The research method uses a pre experimental with a quantitative approach that was conducted in December 2019. The size of the sample in the study were 11 people each group consisting of a control group and an intervention group. The instruments used in this variable include the observation sheet and pain sheet of Bourbonnais to collect data by conducting observations directly to the respondent to find changes or things to be researched. Data collected in statistical tests using Wilcoxon test. The results showed most of the respondents were 7 (63.6\%) Experiencing moderate pain, while the intervention group after the turmeric acid is given that most of the respondents were $6(54.5 \%)$ Experiencing mild pain. Wilcoxon's statistical test results with a significant level of 0.05 are obtained $p=0.001$ so that the $<\alpha 0.05$ is $\mathrm{HO}$ rejected. Advice for students is expected to consume turmeric acid as one of the efforts to relieve dysmenorrhea naturally so as to minimize it if side effects occur.
\end{abstract}

Keyword : consumption, turmeric acid, dysmenorrhea 


\section{LATAR BELAKANG}

Masa pubertas pada remaja ditandai dengan mestruasi tiap bulannya yang berlangsung 5 sampai 7 hari. Menstruasi merupakan peristiwa yang wajar dan alami, walaupun kenyataannya banyak diantara mereka mengalami masalah dysmenorrhoea mulai dari yang ringan sampai berat karena masing-masing wanita memiliki tingkatan nyeri berbeda (Anindita, 2016). Secara psikologis dysmenorrhoea akan sangat mengganggu aktivitas fisik bahkan sampai remaja tidak masuk sekolah (Erikadevi, 2011).

Berdasarkan data WHO (2012) dari 1.769.425 jiwa rata-rata (90\%) wanita mengalami dismenore dengan 85-90\% mengalami gejala dysmenorrhoea ringan. Di Indonesia lebih banyak perempuan yang mengalami dismenore tidak melaporkan atau berkunjung ke dokter. Dikatakan 90\% perempuan Indonesia pernah mengalami dismenore (Gumangsari, 2014). Di Indonesia juga belum ada angka pasti mengenai jumlah penderita nyeri haid (Anindita, 2010).

Berdasarkan hasil wawancara pada Mahasiswi Akbid Harapan Mulya Ponorogo pada tanggal 12 November 2019, dari 10 mahasiswi 8 diantaranya (80\%) mengatakan selalu mengalami dysmenorrhoea saat Menstruasi. Melalui wawancara ini juga terungkap bahwa hampir semua mahasiswa belum tau tentang cara mengatasi dysmenorrhoea. Banyak diantara mereka yang menjawab untuk mengatasi dysmenorrhoea mereka hanya tiduran kalau rasa nyeri berlebihan, dan dari hasil wawancara yang dilakukan oleh peneliti ternyata di Akbid Harapan Mulya Ponorogo tersebut belum pernah tahu tentang konsumsi kunyit Asam untuk mengatasi dysmenorhoe.

Dysmenorhoe merupakan salah satu dari sekian banyak masalah ginekologi, mempengaruhi lebih dari separuh wanita dan menyebabkan gangguan aktivitas terutama awal menstruasi pada wanita tersebut. Gangguan kegiatan sekolah pada remaja akibat dysmenorhoea mencapai $25 \%$, sedangkan pada wanita usia subur mencapai $50 \%$. Solusinya para wanita usia subur dan remaja memerlukan obat anti nyeri suntuk meringankan gejala dysmenorhoea (Anna, 2009).

Mengingat permasalahan tersebut maka peningkatan pengetahuan tentang dysmenorrhoea pada remaja dianggap penting untuk dapat mencari jalan keluar yang terbaik. Pengobatan harus diberikan ketika mengalami nyeri berat, dan pertolongan pertama melalui berbagai ramuan jamu herbal bisa diberikan ketika nyeri yang dialami tidak berat. Untuk mengatasinya maka perlu diusahakan pendekatan dengan baik (Syaifullah, 2010). Banyak obat untuk menurunkan rasa nyeri Dismenorhoe yaitu analgesik seperti Asam Mefenamat dan 
obat lain yang ada di apotik tetapi salah satu cara tradisional yang cukup aman dan efektif adalah dengan mengkonsumsi ramuan kunyit asam.

Kunyit merupakan suplemen nutrisi yang mengandung senyawa kurkumin, jenis alumunium magnesium, seng, zat besi, kalsium, kalium, vitamin A dan C. Asam sendiri mengandung vitamin $\mathrm{B}, \mathrm{C}$, antikosidan, betakaroten dan mineral yang bermanfaat untuk tubuh (Limananti \& Triratnawati dalam Safitri dkk., 2013). Senyawa aktif atau bahan kimia yang terkandung dalam kunyit tersebut adalah curcumine yang bekerja menghambat rekasi cylooxygenase sehingga dapat mengurangi terjadinya inflamasi yang akan mengurangi kontraksi uterus. Kontraksi uterus yang dihambat oleh prostaglandin melalui jaringan epitel uterus oleh curcumine tersebut mampu mengurangi terjadinya dysmenorrhoea pada wanita (Wiesere dalam Safitri dkk., 2013).

Permasalahan lain dalam dysmenorrhoea yang dialami mahasiswa yaitu menjadi kurang fokus dalam proses belajar yang akan mengganggu nilai akademik nantinya. Dari uraian latar belakang diatas, peneliti mengambil judul penelitian pengaruh konsumsi kunyit asam terhadap dysmenorrhoea pada mahasiswa Tingkat I Akademi Kebidanan Harapan Mulya Ponorogo.

\section{METODE}

Pada penelitian ini menggunakan pendekatan kuantitatif, dengan metode preeksperimental design. Penelitian telah dilakukan pada bulan Desember 2019. Besar sampel dalam penelitian sebanyak 11 orang tiap kelompok. Dimana n1 (sampel kelompok eksperimen yang diberikan kunyit asam) sebanyak 11 mahasiswa dan n2 (sampel kelompok kontrol) sebanyak 11 mahasiswa. Instrumen yang digunakan adalah lembar observasi dan lembar penilaian skala nyeri Bourbonnais. Data dikumpulkan melalui pemberian kunyit asam kepada responden selama 3 hari mulai dari haid pertama sampai hari ketiga selama dysmenorrhoea, pemberian sebanyak 3 gelas (450 cc) setiap harinya kemudian di observasi, dan dilakukan pengukuran intensitas nyeri menggunakan lembar penilaian Bourbonnais sebelum dan setelah mengkonsumsi kunyit asam. Data yang sudah terkumpul dilakukan uji statistik denngan uji Wilcoxon. 


\section{HASIL PENELITIAN}

Tabel 1 Distribusi frekuensi intensitas dysmenorrhoea pada Mahasiswa Tingkat I Akbid Harapan Mulya Ponorogo observasi pertama kelompok intervensi dan kontrol sebelum diberikan kunyit asam.

\begin{tabular}{lcccc}
\hline \multirow{2}{*}{ Intensitas nyeri } & \multicolumn{2}{c}{ Kelompok Intervensi } & \multicolumn{2}{l}{ Kelompok Kontrol } \\
\cline { 2 - 5 } & $\mathrm{F}$ & Presentase $(\%)$ & $\mathrm{F}$ & Presentase (\%) \\
\hline Nyeri ringan & 4 & $37.4 \%$ & 6 & $54.5 \%$ \\
\hline Nyeri sedang & 7 & $63.6 \%$ & 5 & $45.5 \%$ \\
Nyeri berat & 0 & 0 & 0 & 0 \\
\hline Jumlah & 11 & $100 \%$ & 11 & $100 \%$
\end{tabular}

Berdasarkan tabel 2.1 didapatkan bahwa sebagian besar responden yaitu 7 orang (63.6\%) mengalami nyeri sedang, sedangkan pada kelompok kontrol pertama sebagian besar responden yaitu 6 orang $(54.5 \%)$ mengalami nyeri ringan.

Nyeri haid biasanya terjadi akibat pelepasan berlebihan prostaglandin tertentu, prostaglandin-F2 $\alpha$ dari sel-sel endometrium uterus. Prostaglandin-F2 $\alpha$ adalah suatu perangsang kuat kontraksi otot polos miometrium dan konstriksi pembuluh darah uterus. Kurangnya oksigen di uterus ketika menstruasi mengakibatkan rasa nyeri hebat terutama pada hari pertama sampai ketiga (Corwin, 2009).

Faktor risiko terjadinya nyeri haid yaitu usia pertama menstruasi sebelum 12 tahun, belum menikah, lama menstruasi lebih dari 7 hari, wanita yang merokok, kebiasaan olahraga yang berlebihan, dan beban pikiran yang tinggi. Penyebab nyeri haid pada kelompok kontrol selain adanya faktor dari dalam seperti faktor endokrin pengeluaran prostaglandin ada juga faktor dari luar yaitu kurangnya berolahraga dan stres. Padatnya jadwal kuliah dan adanya tugas yang harus diselesaikan membuat terbatasnya waktu untuk melakukan olahraga sehingga otot perut menjadi tegang dan menimbulkan nyeri saat haid.

Menurut Harry (2007) menyatakan bahwa rendahnya kegiatan sehari-hari selama menstruasi dan rendahnya melakukan olahraga akan meningkatkan kejadian dysmenorrhoae. Pada uterus terjadi gangguan sirkulasi darah dan penurunan oksigen. Dampaknya uterus mengalami kontraksi sehingga menyebabkan nyeri. 
Tabel 2 Distribusi frekuensi intensitas dysmenorrhoea pada Mahasiswa Tingkat I Akbid Harapan Mulya Ponorogo dari kelompok intervensi sesudah diberikan kunyit asam.

\begin{tabular}{lcccc}
\hline \multirow{2}{*}{ Intensitas nyeri } & \multicolumn{2}{c}{ Kelompok Intervensi } & \multicolumn{2}{c}{ Kelompok Kontrol } \\
\cline { 2 - 5 } & $\mathrm{F}$ & Presentase (\%) & $\mathrm{F}$ & Presentase (\%) \\
& & & & \\
\hline Tidak Nyeri & 3 & $27.3 \%$ & 0 & 0 \\
Nyeri Ringan & 6 & $54.5 \%$ & 6 & $54.5 \%$ \\
Nyeri Sedang & 2 & $18.2 \%$ & 5 & $45.5 \%$ \\
\hline Jumlah & 11 & $100 \%$ & 11 & $100 \%$
\end{tabular}

Berdasarkan tabel 1.2 didapatkan bahwa sebagian besar responden yaitu 6 orang (54.5\%) mengalami nyeri ringan, sedangkan pada kelompok kontrol ke dua didapatkan hasil yang sama yaitu sebagian besar responden yaitu 6 orang $(54.5 \%)$ mengalami nyeri ringan.

Dysmenorhoea merupakan kram pada perut yang dirasakan nyeri ringan sampai berat pada wanita dan biasanya setelah kehamilan pertama akan. Nyeri harus segera ditangani agar tidak terjadi peningkatan intensitas nyeri. Diketahui pada responden kelompok kontrol yang tidak diberikan kunyit asam pada observasi kedua tidak terjadi penurunan intensitas nyeri haid. Hal ini dipengaruhi oleh adanya tingkat kesadaran yang kurang dalam mengupayakan penurunan intensitas nyeri seperti kurangnya kesadaran dalam melakukan pengobatan untuk menurunkan intensitas nyeri haid maupun menghindari faktor yang mempengaruhi intensitas nyeri haid itu sendiri.

Pada kelompok intervensi yang diberikan kunyit asam terjadi perubahan yang dapat dilihat pada table 2.2. Hal ini dikarenakan kunyit merupakan obat alami anti inflamasi atau penghilang rasa sakit saat menstruasi. Kunyit asam dapat menekan pengeluaran prostaglandin dan leukotrin pada endometrium yang mengakibatkan kontraksi kuat sehingga timbul rasa nyeri yang disebut dismenorea atau nyeri haid. 
Tabel 3 Distribusi frekuensi pengaruh Kunyit Asam terhadap intensitas dysmenorrhoea pada Mahasiswa Tingkat I Akbid Harapan Mulya Ponorogo pada kelompok intervensi sebelum dan sesudah diberikan Kunyit Asam.

\begin{tabular}{lcccc}
\hline \multirow{1}{*}{ Kategori } & \multicolumn{4}{c}{ Kelompok intervensi } \\
\cline { 2 - 5 } & \multicolumn{2}{c}{ Sebelum } & \multicolumn{2}{c}{ Sesudah } \\
\hline Tidak nyeri & 0 & 0 & F & $\%$ \\
\hline Nyeri ringan & 4 & $37.4 \%$ & 6 & $27.3 \%$ \\
\hline Nyeri sedang & 7 & $63.6 \%$ & 2 & $18.2 \%$ \\
\hline Nyeri Berat & 0 & 0 & 0 & 0 \\
\hline Total & 11 & 100 & 11 & 100 \\
\hline$p$ value $: 0,001$ & $\alpha 0,05$ & & & \\
& & & & \\
\hline
\end{tabular}

Berdasarkan tabel 1.3 didapatkan bahwa hampir sebagian besar dari responden yaitu 7 $(63.6 \%)$ mengalami nyeri sedang, sedangkan pada kelompok intervensi sesudah diberikan kunyit asam didapatkan bahwa sebagian besar responden yaitu $6(54.5 \%)$ mengalami nyeri ringan.

Berdasarkan perhitungan menggunakan uji statistik Wilcoxon dengan taraf signifikan 0,05 yaitu diperoleh $p=0,001$ sehingga $p<\alpha 0,05$ maka $\mathrm{H}_{0}$ ditolak dan $\mathrm{H}_{1}$ diterima artinya ada Pengaruh Kunyit Asam terhadap intensitas dysmenorrhoea pada Mahasiswa Tingkat I Akbid Harapan Mulya Ponorogo tahun 2019.

Hasil penelitian sesuai dengan apa yang dikatakan Anurogo \& Wulandari (2011) bahwa kunyit (curcumine) sama efektifnya dengan asam mefenamat (mefenamic acid) dan ibuprofen untuk mengurangi nyeri pada wanita dengan nyeri haid atau nyeri haid primer.

Kunyit asam merupakan obat alami yang mengandung penghilang rasa sakit saat menstruasi. Selain itu kunyit asam juga membantu melancarkan aliran darah terutama ketika menstruasi. Pengeluaran prostaglandin dan leukotrin pada endometrium yang mengakibatkan kontraksi uterus menjadi kuat sehingga menyebabkan nyeri haid dapat dikurangi dengan mengkonsumsi kunyit asam (Burner, 2012).

Kunyit merupakan suplemen nutrisi yang mengandung senyawa kurkumin, jenis alumunium magnesium, seng, zat besi, kalsium, kalium, vitamin A dan C. Asam sendiri mengandung vitamin $\mathrm{B}, \mathrm{C}$, antikosidan, betakaroten dan mineral yang bermanfaat untuk tubuh (Limananti \& Triratnawati dalam Safitri dkk., 2013). Senyawa aktif atau bahan kimia yang terkandung dalam kunyit tersebut adalah curcumine yang bekerja 
menghambat rekasi cylooxygenase sehingga dapat mengurangi terjadinya inflamasi yang akan mengurangi kontraksi uterus. Kontraksi uterus yang dihambat oleh prostaglandin melalui jaringan epitel uterus oleh curcumine tersebut mampu mengurangi terjadinya dysmenorrhoea pada wanita (Wiesere dalam Safitri dkk., 2013).

\section{KESIMPULAN DAN SARAN}

Kesimpulan dari penelitian ini adalah ada pengaruh konsumsi kunyit asam terhadap disminorrhea pada mahasiswa Tingkat I Akademi Kebidanan Harapan Mulya Ponorogo. Saran bagi mahasiswa diharapkan untuk mengkonsumsi kunyit asam sebagai salah satu upaya meringankan dysmenorrhea secara alami sehingga bisa meminimalkan apabila terjadi efek samping.

\section{UCAPAN TERIMAKASIH}

Ucapan terima kasih kami ucapkan kepada mahasiswa tingkat I Akademi Kebidanan Harapan Mulya Ponorogo yang bersedia menjadi responden penelitian dan semua pihak yang membantu dalam proses penyusunan penelitian ini.

\section{DAFTAR PUSTAKA}

Alimul, Aziz. (2007) Metodelogi Penelitian Kebidanan Teknik Analisa Data. Jakarta, Salemba Medika.

Anindita, A.Y. 2010. Pengaruh Kebiasaan Mengkonsumsi Minuman Kunyit Asam Terhadap Keluhan Dismenorea Primer Pada Remaja Putri Di Kotamadya Surakarta. Surakarta: Universitas Sebelas Maret

Arikunto, S. (2010) Prosedur Penelitian Suatu Pendekatan Praktik. Jakarta, PT Rineka Cipta

Balita Pustaka . (2001) Kamus Besar Bahasa Indonesia Edisi 3. Jakarta, Balai Pustaka

Beghum, K., Shabnam, O. 2012. Characteristics and Determinants of Primary Dysmenorrhea in Young Adults. American Medical Journal midwiferia, 3 ; 8-13

Hermiyanti. 2012. Pedoman Pelaksanaan Kegiatan Komunikasi, Informasi, Edukasi (KIE) Kesehatan Reproduksi untuk Petugas Kesehatan di Tingkat Pelayanan Dasar. Surabaya : Dinkes Prop Jatim, Depkes RI \& UNFPA

Grandi, G. Ferrari, S, Xholli, A. 2012. Prevalence of Menstrual Pain in Young Women: What is dysmenorrhea. Journal of Pain Research, 5 (2) :169-174.

Gumangsari, Ni Made Gita. 2014, Pengaruh Massage Counterpressure Terhadap Penurunan Tingkat Nyeri Haid Pada Remaja Putri di SMA N 2 Ungaran Kabupaten Semarang, 
Terdapat dalam http://perpusnwu.web.id/karyailmiah/documents/3637.pdf diakses tanggal 20 Desember 2019

Larasati, TA., dan Alatas, F. 2016. Dismenore Primer dan Faktor Risiko Dismenore Primer pada Remaja.Majority. 5 (3) ; 80

Manuaba, I.B. 2011. Kapita Selekta Penatalaksaan Rutin Obstetri Ginekologi dan KB. Jakarta : EGC.

Marlina. 2012. Pengaruh Minuman Kunyit terhadap Tingkat Nyeri Dismenore Primer Pada Remaja Putri di SMA Negeri 1 Tanjung Mutiara Kabupaten Agam. Andalas : Fakultas Keperawatan Universitas Andalas

Rakhama. 2012. Gambaran Derajat Dysmenorrhoea dan Upaya Penanganannya pada Siswi Sekolah Menengah Kejuruan Arjuna Depok Jawa Barat. Jakarta : Fakultas Kedokteran dan Ilmu Kesehatan Universitas Islam Negeri Syarif Hidayatullah

Rahmadhayanti, E., dan Rohmin, A. 2016. Hubungan Status Gizi dan Usia Menarche dengan Dismenorhea Primer pada Remaja Putri Kelas XI SMA Negeri 15 Palembang. Jurnal Kesehatan, 7 (2) ; 255-259

Safitri, M., Tin Utami, Wilis Sukmaningtyas. 2013. Pengaruh Minuman Kunyit Asam terhadap Penurunan Skala Nyeri Haid Primer pada Mahasiswi DIII Kebidanan Tahun 2013. Kebidanan DIII STIKES Harapan Bangsa Purwokerto, Prodi Kebidanan DIII STIKES Harapan Bangsa Purwokerto dan Prodi Kebidanan DIII Akademi Kebidanan Bangka Belitung

Wignjosastro, H. 2010. Ilmu Kebidanan. Jakarta : Yayasan Bina Pustaka Sarwono Prawirohardjo. 